workshop in the control building has been equipped; and the offices on the first floor of the building are in use. Most of the mechanical components of the reactor are being made by Norwegian firms, but the uranium fuel will be supplied by the United Kingdom Atomic Energy Authority and the heavy water by the United States Atomic Energy Commission. The reactor will be operated at low temperatures to begin with, and preliminary investigations have shown that $2 S$-aluminium withstands these low temperatures well and therefore is suitable as canning material for the initial fuel charge.

Information concerning the probable kinetics of the reactor has been obtained through void-coefficient experiments conducted by the physics division and by the use of a reactor simulator which was built specially for this purpose. The simulator consists of an analogue computer, loaned by the Norwegian Defence Research Establishment, to which has been added various units for the simulation of reactor kinetics and xenon poisoning and a multiplier circuit.

The nuclear ship-propulsion group has concentrated its attention on the use of uranium oxide - light water lattices for ship reactors. Parametric analyses of various fuel-moderator systems have been carried out, and optimization studies of reactor plant components have been made. Problems relating to both normal as well as adverse operational conditions, such as collisions at sea, groundings, fire and ex. plosion hazards, have been considered and discussed with the appropriate Norwegian maritime authorities.

In addition to the void-coefficient experiments the physics division has continued its exponential experi. ments on heavy water - natural uranium lattices which it is carrying out in eo-operation with A. B. Atomenergi at Stockholm. A report of measurements on clean lattices has been published $(J$. Nuclear Engineer. ing, 3 ; 1956) and a report on cluster type rods has been issued by A. B. Atomenergi (AEF-65). A Nonius general-purpose camera has been added to the $\mathrm{X}$-ray equipment and X-ray work has been mainly concentrated on phosphoric acid. The investigation of capture gamma circular polarization has continued and work on the gamma-spectrum of fission has been started. The health physics service of the Establishment was intensified during the period under review and the report mentions that only one member of the staff received a dose in excess of $5 \mathrm{r}$. and that 81 per cent received less than $1 \mathrm{r}$. The service controls about 150 persons.

Details are also given in the annual report of the production and shipments of radioisotopes; of the activities of the chemistry and metallurgical sections of the Establishment ; of the reports and publications published by the Establishment and members of the staff ; of the Establishment's reactor courses and of the new reactor school being opened in 1958 with a nine-week full-time postgraduate course in fundamentals of nuclear engineering; and of the personnel and accounts of the Establishment.

\title{
RESEARCH AND DEVELOPMENT IN THE B.B.C.
}

$\mathrm{A}^{\mathrm{N}}$

PART from the maintenance and steady improvement of a nation-wide sound and television service, the manner in which the Engineering Division of the B.B.C., and particularly of its Research and Designs Departments, continues to make technical progress, is well illustrated by the B.B.C. Engineering Division Monographs, of which Nos. 15-19 have been published during the past few months* (reference was made to Nos. $12-14$ in Nature, 181, 1046 ; 1958). These deal with a variety of subjects, from the quantitative measuring technique which is a necessary tool in the transmission and reproduction of high-quality sound to an appraisal of the results of the experiments made by the B.B.C. in colour television.

Monograph No. 15, entitled "New Equipment and Methods for the Evaluation of the Performance of Lenses for Television", outlines the photo-electric method of testing lenses and describes a new optical bench developed for the purpose. The factors affecting the quality of a television picture are discussed, and formulæ are developed on an experimental basis for an index of quality for both monochrome and colour television.

The analysis and measurement of the extremes of sound programme-levels are dealt with in Monograph

* B.B.C. Engineering Monographs. No. 15: New Equipment and Methods for the Evaluation of the Performances of Lenses for Television. By W. N. Sproson. Pp 16. No. 16: Analysis and Measurement of Programme Levels. Part 1 . Investigation of Extreme Values of Sound Pressure. By D. E. L. Shorter and W. I. Manson. Part 2: A By E. R. Wigan. Pp. 31. No. 17: The Design of a Linear PhaseShift Low-Pass Filter. By J. E. Weaver. Pp. 23. No. 18: The B.B.C. Colour Television Tests-an Appraisal of Results. 18 ; The Sproson, S. N. Watson and M. Campbell. Pp. 39. No. 19: A V.H.F. Television Link for Outside Broadcasts. By K. C. Quinton. Pp. 20 (London: British Broadcasting Corporation, 1957 and 1958.) 5s. each.
No. 16 in two parts: (1) "Investigation of Extreme Values of Sound Pressure", by D. E. L. Shorter and W. I. Manson ; and (2) "A Description of an Optical Instrument for Monitoring Sound Signals", by E. R. Wigan. An optical projection type of instrument has been developed, the range of indication of which is sufficient to deal with the most difficult programme material. While the instrument has a limited field of application to sound broadcasting, it has obvious advantages for the control of sound channels in television.

"The Design of a Linear Phase-Shift Low-Pass Filter", by L. E. Weaver (Monograph No. 17), describes the theoretical and practical details of the design of a very linear phase-shift low-pass filter intended to remove noise and other irrelevant information above approximately $3 \mathrm{Mc} / \mathrm{s}$. from the output of a television camera control unit. A "Note on Random Fluctuation Noise in Image Orthicon Camera Tubes", by R. D. A. Maurice, is appended and revises some of the conclusions in an earlier monograph on the distribution of noise over the grey scale of a picture.

Monograph No. 18 forms an interesting highlight in the series under review and is entitled "The B.B.C. Colour Television Tests : an Appraisal of Results", by W. N. Sproson, S. N. Watson and M. Campbell. This describes the results of field trials condueted during 1955-57 in viewers' homes by the Research and Designs Departments of the Corporation after preliminary experiments and the development of suitable receivers in the laboratory. Since the tests were completed, a further series was carried out during 1957-58 and the results are now being analysed. 
'The field trials on which the B.B.C. now reports extended over a total period of seventeen months and involved the analysis of more than a thousand questionnaires, filled in by members of the B.B.C. staff and others who watched the results on special sets. So far as reception of the colour picture is concerned, the B.B.C.'s verdict is that the colour pictures produced by the N.T.S.C. system as adapted to 405 lines, with the picture sources and display tubes that are at present available, are satisfactory. The problem of registration with the three-tube colour camera requires attention, and certain features of the display tube could with advantage be improved, but the technical performance of the system is adequate for a satisfactory colour television service in the frequency bands at present in use. The tests radiated from Crystal Palace during November 1956-April 1957 included live studio performances, film and slides. Of the observers, 89 per cent regarded the reception of the live scenes as satisfactory. The $35-\mathrm{mm}$. film was regarded as satisfactory by 100 per cent of the observers, the $16-\mathrm{mm}$. film by 93 per cent, and the slides by 98 per cent. The compatibility of the transmissions was very good indeed. This means that the quality of ordinary black and white television, when received on a colour television set, was found to be generally satisfactory; and likewise the quality of the colour transmissions, when received in black and white on ordinary television sets, was completely acceptable to 94 per cent of technical observers.

The results of the tests have been communicated to the Television Advisory Committee, which has the task of advising the Postmaster-General on the whole field of television. The results have also been sent to the International Radio Consultative Committee which recently met in Moscow to consider colour television. The B.B.C. will carry out further experimental transmissions from time to time. It is pointed out that there are many other problems to be solved: for example, the production of a reasonably priced colour-receiving set and agreement on the future standards to be applied to the development of television in the United Kingdom. The decision whether or not there is to be a public service of colour television, and if so the system to be used, rests with the Postmaster-General.

A national television network requires to be adequately supported by inter-connecting line and radio links capable of transmitting without distortion the complex signals conveying the sound and vision information. Where outside broadcasts are con. cerned, mobile equipment is usually necessary, and the design and development of such equipment is described in Monograph No. 19, by K. C. Quinton, under the title "A V.H.F. Television Link for Outside Broadcasts". This provides, first, a brief historical introduction to the problems of radio linkage, leading to the need for using ultra-high frequencies, with particular reference to moving-camera applications and to propagation over water. The relative merits of amplitude and frequency modulation are explored in theory and practice; and details are given of the equipment developed for use in the frequency-range $610-660 \mathrm{Mc} / \mathrm{s}$. The first year's operational experience with such equipment has been very successful.

\section{ROAD RESEARCH}

T HE work of the Road Research Laboratory is concerned partly with the behaviour of traffic on the road, and partly with the performance of materials and with the methods of construction of the road itself. The Laboratory's annual report for $1957^{*}$ is interesting and well presented.

Some problems of traffic and safety can be solved by a controlled experiment. For example, the Laboratory conducted a full-scale experiment with streams of traffic weaving through each other as the vehicles entered and left a roundabout. This led to an empirical formula, from which the limiting traffic flow could be predicted accurately. The Laboratory has also developed an apparatus for measuring accurately the resistance of a road surface to skidding; one graph shows a seasonal variation of this resistance which corresponds closely with the seasonal variations in the number of skidding accidents.

To study other problems, the Laboratory conducts various field surveys. For example, a survey of the flow of traffic in the streets of London and Glasgow showed an average journey-speed of ten miles per hour with vehicles stopped for about a third of their journey time. Detailed field studies of accidents suggest that the doors of British cars tend to jam in a crash, while the doors of American cars tend to fly open. Their conclusion from a study of reports of a sample of fatal accidents was that 13 or 14 per

* Department of Scientific and Industrial Research. Road Research 1957: The Report of the Road Research Board with the Report of the Direct or of Road Research. Pp. iv $+93+8$ plates. (London H.M. Stationery Office, 1958.) 5s. 6d. net. cent of fatal accidents involved a person who had drunk alcohol (the official statistics suggest a figure of only 2 per cent), and showed further that, "one half of the drivers and more than one half of the pedestrians involved in fatal accidents at night had been drinking".

Experiments to reduce accidents have sometimes been very successful : a big roundabout can eliminate three-quarters, and a smaller roundabout a half, of the accidents at an intersection. Sometimes success is more elusive. A full-scale attempt to reduce road casualties in Slough over a two-year period produced only an "apparent reduction" compared with the increasing numbers of casualties in Great Britain as a whole, which must have been something of a disappointment. Perhaps it was a mistake for the Laboratory to be too much concerned with traffic conditions in a town so close at hand.

In the work on materials and methods of construction a major experimental section of road has been constructed as part of the new north-bound carriageway of the Great North Road at Alconbury Hill in Huntingdonshire : there are seventy different variations in the pavement construction within a length of $2 \frac{1}{4}$ miles, although the passing motorist is probably only aware of the changes at one or two points in this length. This experiment is concerned with fairly conventional pavement construction, but it is interesting to read of the continued satisfactory performance of some other experiments of previous years when lengths of cement-stabilized gravel base 